\title{
Advanced Mechanical Ventilatory Constraints During Incremental Exercise in Class III Obese Male Subjects
}

\author{
Mehdi Chlif PhD, Abdou Temfemo PhD, David Keochkerian PhD, Dominique Choquet PhD, \\ Anis Chaouachi PhD, and Said Ahmaidi PhD
}

\begin{abstract}
BACKGROUND: We investigated the role of mechanical ventilatory constraints in obese class III subjects during incremental exercise. METHODS: We examined 14 control subjects (body mass index [BMI], $23.6 \pm 3.2 \mathrm{~kg} / \mathrm{m}^{2}$ ), 15 obese class II subjects (BMI, $37.2 \pm 4.5 \mathrm{~kg} / \mathrm{m}^{2}$ ), and 17 obese class III subjects (BMI, $53.4 \pm 6.8 \mathrm{~kg} / \mathrm{m}^{2}$ ). All subjects performed pulmonary function tests and maximal inspiratory pressure at rest, ventilatory parameters, flow-volume loops, and rated perceived exertion and breathlessness during exercise. RESULTS: All subjects had normal pulmonary function. Obesity resulted in increased minute ventilation for a given submaximal work rate, although minute ventilation during peak exercise was lowest in the obese class III subjects. Endexpiratory lung volume was significantly lower in the obese subjects at rest and during exercise at the ventilatory threshold but not during peak exercise. During heavy-to-peak exercise, the obese subjects increased their end-expiratory lung volume, whereas the control group continued to decrease this parameter. Compared with controls, end-inspiratory lung volume was significantly lower in obese class II subjects and obese class III subjects at rest and at the ventilatory threshold but not during peak exercise. At maximal exercise, obese class III subjects had a greater endinspiratory lung volume than obese class II subjects and controls. Obese class III subjects displayed a greater expiratory air flow limitation at rest, at the ventilatory threshold, and during peak exercise than both controls and obese class II subjects. CONCLUSIONS: Mechanical ventilatory constraints increase progressively with degrees of obesity, contributing to exercise limitation in obese subjects. Key words: end-expiratory lung volumes; end-inspiratory lung volume; expiratory air flow limitation; breathing strategy; work of breathing; dyspnea. [Respir Care 2015;60(4):549-560.

(C) 2015 Daedalus Enterprises]
\end{abstract}

\section{Introduction}

Ventilatory limitation during exercise has traditionally been determined by measuring how close the minute ven-

Drs Chlif, Temfemo, Keochkerian, Choquet, and Ahmaidi are affiliated with the Sport Science Department, Picardie Jules Verne University, F-80025 Amiens Cedex, France; Drs Chlif and Chaouachi are affiliated with the Tunisian Research Laboratory Sport Performance Optimization, National Center of Medicine and Science in Sports, Tunis, Tunisia; Dr Choquet is also affiliated with the Department of Cardiac Rehabilitation, Corbie Hospital, Corbie, F-80800 Corbie, France.

The authors have disclosed no conflicts of interest.

Correspondence: Mehdi Chlif PhD, Faculté des Sciences du Sport Allée P Grousset Campus Universitaire du Bailly F-80025, Amiens Cedex, France. E-mail: mehdi.chlif@gmail.com.

DOI: $10.4187 /$ respcare.03206 tilation $\left(\dot{\mathrm{V}}_{\mathrm{E}}\right)$ achieved during exercise approaches the maximum voluntary ventilation (MVV). However, the ventilatory reserve $\left(\dot{\mathrm{V}}_{\mathrm{E}} / \mathrm{MVV}\right)$ ratio is relatively insensitive and tells us little about the specific reasons for ventilatory constraint. ${ }^{1}$ In obese subjects, breathing at a low lung volume (near the residual volume) limits the available ventilatory reserve due to (1) the shape of the expiratory flowvolume curve, (2) reduced maximal available air flows, and (3) reduced chest wall compliance. The breathing reserve using the MVV therefore only provides limited information, and does not provide insight into breathing strategy or the degree of expiratory or inspiratory flow constraints. ${ }^{1}$ Understandably, significant controversy surrounds assessment of the ventilatory reserve, partly because of the lack of a definitive method for measuring ventilatory capacity. Nevertheless, emerging technologies (such as specific exercise tidal flow-volume loops referenced to maximal flow-volume loops) have provided valu- 
able additional insight into how mechanical constraints limit exercise. ${ }^{2}$

In mild to moderate obesity, the earliest and most prominent change in pulmonary function is a reduction in endexpiratory lung volume (EELV), which is specific to static respiratory mechanics. ${ }^{3}$ In the present study, we chose to monitor EELV, which is determined by both respiratory mechanics and respiratory muscle recruitment during exercise. The end-expiratory lung volume adopted during exercise is also influenced by expiratory flow limitation. ${ }^{3}$ Importantly, a change in EELV is a major component of the normal ventilatory response to exercise and reflects alterations in respiratory mechanics during exercise. The EELV adopted during exercise has serious implications for tidal expiratory flow, respiratory muscle function, work of breathing (WOB), and/or shortness of breath. ${ }^{2,4} \mathrm{Re}$ cently, a number of studies have reported that mild to moderate obesity does not appear to limit the decrease in EELV during mild to moderate intensity cycling exercise. ${ }^{5-7}$ However, the obesity-associated reduction in EELV at rest appears to influence the regulation of this parameter during heavy-to-peak exercise. This may occur when the obese subject is placed at a lung volume that predisposes him/her to high expiratory resistance and expiratory flow limitation, which necessitates an increase in EELV to augment $\dot{V}_{E}$ proportionally with exercise intensity.5,6,8

However, the degree of ventilatory constraint in massive obesity has yet to been defined. To our knowledge, a systematic study of progressive mechanical ventilatory constraints during exercise in obese class III individuals has never yet been conducted. It has been suggested that the decline in pulmonary function may be relatively greater in obese class III patients than in obese class II patients, thus making the former more susceptible to mechanical ventilatory constraints during exercise.

To investigate the progressive nature of mechanical ventilatory constraints in obesity, we chose to study 14 control, 15 obese class II, and 17 obese class III subjects. We hypothesized that lung function would progressively decrease with obesity and that obese class III subjects would experience greater mechanical ventilatory constraints during exercise.

\section{Methods}

\section{Subjects}

Three groups of male subjects were recruited through local advertisements. Fourteen control (BMI $=23 \pm$ $3 \mathrm{~kg} / \mathrm{m}^{2}$ and $40 \pm 5 \mathrm{y}$ of age), 15 obese class II $\left(B M I=37 \pm 4 \mathrm{~kg} / \mathrm{m}^{2}\right.$ and $42 \pm 8 \mathrm{y}$ of age), and 17 obese class III $\left(\right.$ BMI $=53 \pm 6 \mathrm{~kg} / \mathrm{m}^{2}$ and $45 \pm 4 \mathrm{y}$ of age) subjects were included in the study. Subjects provided verbal and written informed consent in accordance with

\section{QUICK LOOK}

\section{Current knowledge}

Ventilatory limitation during exercise is commonly determined by measuring the relationship of the minute ventilation achieved during exercise to the maximum voluntary ventilation. However, this ratio is relatively insensitive and cannot identify the specific reasons for ventilatory constraint. In obese subjects, breathing at a low lung volume limits the available ventilatory reserve due to alterations in pulmonary and chest wall mechanics.

\section{What this paper contributes to our knowledge}

The impaired exercise performance in obese subjects was largely a result of increased ventilatory loads and impaired ventilatory muscle function. In subjects with severe obesity (class III), a reduced tidal volume reserve required an increase in breathing frequency to elevate minute volume, leading to dynamic hyperinflation. This additional elastic load was associated with exertional dyspnea, hypoxemia, and exercise limitation.

the guidelines established by the institutional review board. The experimental procedures complied with the ethical standards of the 1975 Helsinki Declaration, and approval was received from the appropriate local institutional review board. All qualified participants were familiarized to exercise on the cycle ergometer and instructed to avoid exercise, food, and caffeine for at least $2 \mathrm{~h}$ before exercise testing, or had participated in regular vigorous exercise for the last 6 months. The American Thoracic Society spirometry interpretation workshop only states that subjects should be "never-smokers, free of respiratory symptoms and disease." In accordance with these guidelines, exclusion criteria included: the presence of a significant disease other than obesity that could contribute to dyspnea or exercise limitation (ie, metabolic, cardiovascular, neuromuscular, musculoskeletal, history of asthma or COPD, smoking history, obstructive sleep apnea, pulmonary hypertension, obesity hypoventilation or other respiratory diseases, syndromes, or musculoskeletal abnormalities). ${ }^{10}$ Subjects not meeting these guidelines were excluded.

\section{Body Composition}

Standard measures of height, weight, waist, and hip circumferences were made upon initial screening of subjects. BMI and waist-to-hip ratio (WHR) were calculated from the standard measures. 


\section{Pulmonary Function Test}

Baseline spirometric function was measured (Vmax 2130 spirometer, SensorMedics, Anaheim, California) with the subjects seated on the cycle ergometer before the exercise test. The subjects completed at least 3 acceptable maximal forced expiratory maneuvers; technical procedures, acceptability, and reproducibility criteria were those recommended by the American Thoracic Society/European Respiratory Society. ${ }^{11}$ Forced vital capacity $(\mathrm{FVC}), \mathrm{FEV}_{1}$, and peak expiratory flow were recorded at body temperature and pressure saturated (BTPS). Predictive values were taken from Castellsagué et al. ${ }^{12}$

Body plethysmography and maximum inspiratory capacity were performed (V6200 Autobox, SensorMedics, Yorba Linda, California) in accordance with recommended techniques. ${ }^{11}$ Pulmonary function measurements were standardized as percentage of predicted normal values; predicted normal inspiratory capacity (IC) was calculated as predicted TLC minus predicted functional residual capacity. ${ }^{11}$

\section{Maximal Inspiratory Pressure}

At rest, maximal inspiratory pressure $\left(\mathrm{P}_{\mathrm{Imax}}\right)$ was measured at the functional residual capacity on seated subjects at rest, with a differential pressure transducer (Druck, LPM 9000 series, $\pm 350 \mathrm{~cm} \mathrm{H}_{2} \mathrm{O}$, Leicester, United Kingdom) using the technique of Black and Hyatt. ${ }^{13}$ Predictive values were those of Harik-Khan et al. ${ }^{14}$

\section{Flow-Volume Measurements}

Tidal flow-volume loops were measured by the Vmax 2130 cardiopulmonary exercise testing (SensorMedics, Yorba Linda, California) at rest, before exercise, and during the last $30 \mathrm{~s}$ of each exercise intensity. Maximal flowvolume maneuvers were performed in conjunction with the tidal breaths at rest and during each exercise intensity, as well as within 2 min post exercise. The tidal flowvolume loops were collected without perception by the subjects. Literature shows that IC maneuvers do not interfere with the main cardiorespiratory functional parameters used for the interpretation of the cardiopulmonary parameters during incremental exercise. ${ }^{15}$ Typically, IC maneuvers were performed after $5-8$ tidal breaths were collected with instructions to take a deep inspiration to total lung capacity (TLC). This was with an additional 5 breaths and a second IC maneuver followed by an FVC maneuver. On analysis, drift in the volume signal was corrected by aligning the tidal breaths according to the 2 IC maneuvers (assuming that TLC did not change). The IC maneuver was practiced repeatedly at rest before exercise to help ensure that a complete inspiration would be accomplished throughout the exercise period. The coefficient of variation for obese subjects and controls for multiple IC maneuvers that were performed before exercise averaged $<6 \%$.

\section{Breathing Mechanics}

Inspiratory capacity was measured at rest and during exercise to determine placement of tidal flow-volume loops within the maximal flow-volume loop as previously described. ${ }^{16}$ End-expiratory lung volume was estimated from measurement of IC $($ EELV $=[$ TLC $]-$ IC) and reported as a percentage of TLC (EELV, \% TLC). End-inspiratory lung volume (EILV) was calculated (EILV $=E E L V+$ ventilatory threshold [VT]) and expressed as a percentage of TLC (EILV, \% TLC). This assumes that TLC does not change significantly with body position ${ }^{17}$ or exercise. ${ }^{6,18,19}$

\section{Expiratory Air Flow Limitation}

To evaluate the degree of ventilatory constraint during exercise, the degree of expiratory flow limitation can be examined by plotting the exercise flow-volume loop relative to the maximal flow. ${ }^{2}$ This relationship can provide information about the degree of expiratory flow limitation, operating lung volumes, as well as breathing strategies used with incremental exercise. The degree of expiratory air flow limitation is therefore a balance between ventilatory demand and ventilatory capacity combined with the way subjects choose to regulate their EELV. ${ }^{3}$

EAFL was defined as the $\%$ tidal volume where tidal expiratory flow impinged on maximal expiratory flow. As the degree of expiratory flow limitation increases, EELV typically rises (dynamic hyperinflation) and the inspiratory elastic load increases. ${ }^{4,20}$

\section{Exercise Protocol}

Exercise testing was performed on a cycle ergometer (Ergometrics 800S, SensorMedics, Anaheim, California). After $3 \mathrm{~min}$ of baseline measurements, the subjects performed an incremental exercise. ${ }^{21}$ Thereafter, the work rate was increased incrementally in 1-min intervals until a symptom-limited end point was reached. The individualized exercise test protocol used in our laboratory usually results in a maximal oxygen uptake (maximum $\dot{\mathrm{V}}_{\mathrm{O}_{2}}$ ) test duration of 8-12 min meeting standard exercise testing recommendations. Exercise variables were measured and averaged over the last $30 \mathrm{~s}$ of 1 -min increments and at peak exercise. All subjects were encouraged to exercise until exhaustion or they felt unable to continue. Test termination criteria included volitional exhaustion, pedal rate 
note maintained at $50 \mathrm{rpm}$ at each level of exercise and a leveling of oxygen uptake. Peak $\dot{\mathrm{V}}_{\mathrm{O}_{2}}$ was defined as the highest $\dot{\mathrm{V}}_{\mathrm{O}_{2}}$ that could be sustained for at least $30 \mathrm{~s}$ during the last stage of exercise.

Both inspiratory and expiratory air flow were obtained from the calibrated mass flow sensor (Vmax 2130 metabolic measurement system, Sensor Medics) and electronically integrated to obtain volume measurements. Measurements of $\dot{\mathrm{V}}_{\mathrm{O}_{2}}$ and carbon dioxide production $\left(\dot{\mathrm{V}}_{\mathrm{CO}_{2}}\right)$ were made with the use of a computerized custom gas exchange. VT was determined as described previously. ${ }^{21,22}$ Three validated methods were used concurrently to determine VT from incremental exercise test data: (1) ventilatory equivalent method $\left(\dot{\mathrm{V}}_{\mathrm{E}} / \dot{\mathrm{V}}_{\mathrm{O}_{2}}\right.$ method), ${ }^{23,24}$ (2) excess carbon dioxide method $\left(\mathrm{P}_{\mathrm{ETCO}}\right),{ }^{2}, 2,24$ and (3) modified $\mathrm{V}$ slope method. ${ }^{25}$ This point was measured in a double blind design, according to the best agreement between 2 independent observers. In case of disagreement (ie, more than $10 \%$ difference between the 2 observers), a third investigator was asked to assess the thresholds. The value retained was the average of the values in closer agreement. We used VT to differentiate between light-to-moderate and heavy-to-maximal exercise. Ventilatory threshold was designated as the work rate that was most congruent among the different threshold determination methods. Electrocardiography and pulse oximetry were carried out continuously, and blood pressure was taken by auscultation at rest, at the end of each stage of exercise, at peak exercise, and during recovery from exercise. $\mathrm{S}_{\mathrm{pO}_{2}}$ was measured noninvasively with a pulse oximeter (Avant 9600) at the finger to detect exercise-induced hypoxemia, which was defined as a drop in $\mathrm{S}_{\mathrm{pO}_{2}}>$ of 3-4\% between rest and the end of the exercise. ${ }^{26} \Delta \mathrm{S}_{\mathrm{pO}_{2}} \%$ was designated as arterial oxygen desaturation as indicated, by pulse oximetry $\left(\mathrm{S}_{\mathrm{pO}_{2}}\right.$ rest $-\mathrm{S}_{\mathrm{pO}_{2}}$ maximal exercise). The modified Borg scale was used to record rating of perceived breathlessness (RPB) and perceived exertion at peak exercise. ${ }^{27}$ To avoid possible effects of performing IC maneuvers on dyspnea intensity, IC maneuvers were always performed after subjects completed symptom intensity ratings.

A minimum of 2 IC were measured during the last $30 \mathrm{~s}$ of each work load by having the subject, on cue from the investigator, inhale maximally from a stable EELV to TLC. Changes in EELV were inferred from these IC measurements. ${ }^{20}$ Maximal flow-volume loops were determined $2 \mathrm{~min}$ after termination of exercise to determine whether exercise had induced bronchodilation or bronchoconstriction. ${ }^{2,20}$

\section{Data Analysis}

For each subject tested, 2 drift-corrected tidal flowvolume loops were averaged for rest and at each exercise intensity. The average loops were then plotted separately within each subject's maximum flow-volume envelope (obtained at the same specific time point) to assess the degree of ventilatory constraint.

The degree of expiratory flow limitation was defined as the degree to which the tidal flows during exercise met or exceeded the maximum flow-volume envelope measured during the same time period. ${ }^{28}$ The expiratory flow limitation was expressed as the percentage of the tidal volume over which expiratory flow met or exceeded the maximum flow-volume envelope flow at the same lung volume. ${ }^{20}$

The ventilatory response to exercise was determined below and above ventilatory threshold by least squares regression as described previously. ${ }^{5,6}$ The slope was calculated according to the method of Wasserman et al. ${ }^{29}$ For accurate calculation, we discarded any irregularities at the start (ie, the first 1 or $2 \mathrm{~min}$ ) of exercise or any plateau near the end of exercise, because the lactate threshold could potentially distort the response's linearity. The slope of $\dot{V}_{E}$ versus work rate was calculated individually on all the points between rest and VT and between VT and peak exercise for controls, obese class II, and obese class III groups, respectively. The fit of these data were considered good based upon the average coefficient of determination $\left(\mathrm{r}^{2}\right)$, which, below VT was $0.97 \pm 0.04,0.94 \pm 0.06$, and $0.91 \pm 0.07$ and, above VT, was $0.95 \pm 0.05,0.92 \pm 0.05$, and $0.90 \pm 0.06$ for controls, obese class II, and obese class III groups, respectively. The individual slopes were then averaged and used as indicators of ventilatory response below and above VT. To compare the $\dot{\mathrm{V}}_{\mathrm{O}_{2}}$ and work rate relationship across groups that used different increments in work rate, we utilized the above method to calculate the slope of $\dot{\mathrm{V}}_{\mathrm{O}_{2}}$ versus work rate between the initial work rate and VT. The average $\mathrm{r}^{2}$ below VT was $0.98 \pm 0.05,0.97 \pm 0.04,0.96 \pm 0.03$ and, above VT, the average was $0.98 \pm 0.04,0.96 \pm 0.02$, and $0.94 \pm 0.06$ for controls, obese class II, and obese class III groups, respectively.

\section{Statistics}

Differences between groups were determined with a oneway analysis of variance (groups $\times$ exercise intensity). When the one-way analysis of variance-F ratio was significant, the post hoc Bonferroni test was used to perform pairwise multiple comparisons. When the difference between only 2 means was to be tested (ie, slopes below and above VT), paired $t$ tests were used. Relationships among variables were determined by Pearson correlation coefficients. Values are presented as means $\pm \mathrm{SD}$. A $P$ value $<.05$ was considered significant. 
Table 1. Subject Characteristics

\begin{tabular}{|c|c|c|c|}
\hline & $\begin{array}{c}\text { Control } \\
(n=14)\end{array}$ & $\begin{array}{c}\text { Obese } \\
\text { Class II } \\
(n=15)\end{array}$ & $\begin{array}{l}\text { Obese } \\
\text { Class III } \\
(n=17)\end{array}$ \\
\hline Age $(y)$ & $40 \pm 5$ & $42 \pm 8$ & $45 \pm 4$ \\
\hline Height (cm) & $170 \pm 11$ & $168 \pm 12$ & $164 \pm 13$ \\
\hline Weight (kg) & $65 \pm 6.5^{*}$ & $103 \pm 9 \dagger$ & $141 \pm 22 \ddagger$ \\
\hline BMI $\left(\mathrm{kg} / \mathrm{m}^{2}\right)$ & $23.6 \pm 3.2^{*}$ & $37.2 \pm 4.5 \dagger$ & $53.4 \pm 6.8 \ddagger$ \\
\hline WHR & $0.80 \pm 0.05 \S$ & $0.97 \pm 0.04 \|$ & $1.01 \pm 0.04 \ddagger$ \\
\hline \multicolumn{4}{|c|}{ 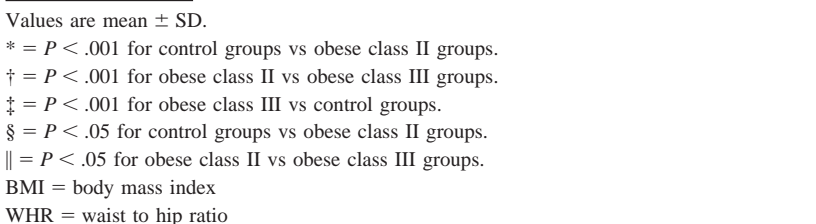 } \\
\hline
\end{tabular}

Table 2. Pulmonary Function Test Results

\begin{tabular}{|c|c|c|c|}
\hline & $\begin{array}{c}\text { Control } \\
(n=14)\end{array}$ & $\begin{array}{l}\text { Obese } \\
\text { Class II } \\
(n=15)\end{array}$ & $\begin{array}{c}\text { Obese } \\
\text { Class III } \\
(n=17)\end{array}$ \\
\hline $\mathrm{FEV}_{1}(\%$ pred $)$ & $123 \pm 6^{*}$ & $105 \pm 7 \|$ & $95 \pm 14 \ddagger$ \\
\hline FVC (\% pred) & $110 \pm 11$ & $104 \pm 18 \S$ & $89 \pm 20 \ddagger$ \\
\hline $\mathrm{FEV}_{1} / \mathrm{FVC}(\%$ pred $)$ & $100 \pm 7$ & $99 \pm 8 \dagger$ & $81 \pm 6 \ddagger$ \\
\hline PEF (\% pred) & $114 \pm 12$ & $108 \pm 20 \|$ & $85 \pm 25 \ddagger$ \\
\hline TLC (\% pred) & $99 \pm 8$ & $93 \pm 11 \dagger$ & $75 \pm 10 \ddagger$ \\
\hline $\mathrm{P}_{\text {Imax }}(\%$ pred $)$ & $99 \pm 8^{*}$ & $77 \pm 12 \S$ & $69 \pm 11 \ddagger$ \\
\hline \multicolumn{4}{|c|}{ 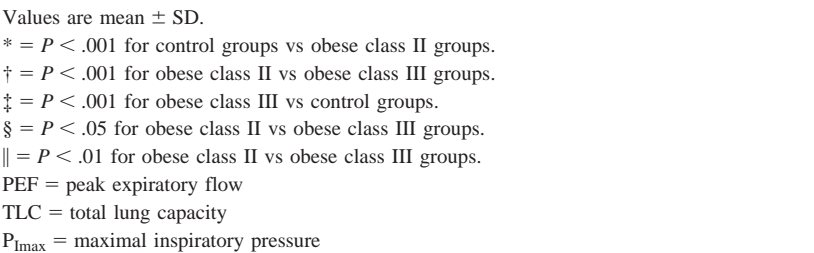 } \\
\hline
\end{tabular}

\section{Results}

\section{Subjects}

Subject characteristics are shown in Table 1. Weight, BMI, and waist circumference/hip circumference were all significantly greater in the obese groups $(P<.001)$. No differences were noted for age and height.

\section{Pulmonary Function}

Pulmonary function data are presented in Table 2. Based on predicted values, all subjects had normal spirometry parameters. However, predicted TLC values decrease in obese class III in agreement with other studies, ${ }^{30-32}$ and obesity resulted in a progressive decrease in $\mathrm{FEV}_{1}, \mathrm{FVC}$, $\mathrm{FEV}_{1} / \mathrm{FVC}$ ratio, peak expiratory flow, and TLC. Addi-
Table 3. Maximal Exercise Values

\begin{tabular}{|c|c|c|c|}
\hline & $\begin{array}{l}\text { Control } \\
(n=14)\end{array}$ & $\begin{array}{c}\text { Obese } \\
\text { Class II } \\
(n=15)\end{array}$ & $\begin{array}{l}\text { Obese } \\
\text { Class III } \\
(n=17)\end{array}$ \\
\hline WR (W) & $170 \pm 40^{*}$ & $120 \pm 30 \dagger$ & $90 \pm 20 \ddagger$ \\
\hline$\dot{\mathrm{V}}_{\mathrm{O}_{2}}(\%$ pred $)$ & $88 \pm 9$ & $82 \pm 10 \dagger$ & $75 \pm 8 \ddagger$ \\
\hline$\dot{\mathrm{V}}_{\mathrm{E}}(\mathrm{L} / \mathrm{min})$ & $100 \pm 20 \S$ & $80 \pm 17 \dagger$ & $52 \pm 11 \ddagger$ \\
\hline HR (\% pred) & $94 \pm 5$ & $92 \pm 6 \dagger$ & $82 \pm 8 \ddagger$ \\
\hline RER & $1.3 \pm 0.07 *$ & $1.16 \pm 0.07 \dagger$ & $0.99 \pm 0.08 \ddagger$ \\
\hline$\dot{\mathrm{V}}_{\mathrm{E}} / \mathrm{MVV}(\%)$ & $65 \pm 11$ & $67 \pm 12 \dagger$ & $85 \pm 9 \ddagger$ \\
\hline RPE, 6-20 scale & $18 \pm 1$ & $18 \pm 2$ & $18 \pm 2$ \\
\hline RPB, 0-10 scale & $6 \pm 3 \|$ & $8 \pm 2$ & $9 \pm 1 \ddagger$ \\
\hline$\Delta \mathrm{S}_{\mathrm{pO}_{2}}(\%)$ & $-1 \pm 2$ & $-3 \pm 2 \dagger$ & $-6 \pm 3 \ddagger$ \\
\hline \multicolumn{4}{|c|}{$\begin{array}{l}\text { Values are mean } \pm \mathrm{SD} \text {. } \\
*=P<.001 \text { for control groups vs obese class II groups. } \\
\dagger=P<.001 \text { for obese class II vs obese class III groups. } \\
\ddagger=P<.001 \text { for obese class III vs control groups. } \\
\S=P<.01 \text { for control groups vs obese class II groups. } \\
\|=P<.05 \text { for obese class II vs obese class III groups. } \\
\mathrm{WR}=\text { work rate } \\
\dot{\mathrm{V}}_{\mathrm{O}_{2}}=\text { oxygen uptake } \\
\dot{\mathrm{V}}_{\mathrm{E}}=\text { minute ventilation } \\
\mathrm{HR}=\text { heart rate } \\
\mathrm{RER}=\text { rate of exchange ratio } \\
\mathrm{MVV}=\text { maximal voluntary ventilation } \\
\mathrm{RPE}=\text { rating of perceived exertion } \\
\mathrm{RPB}=\text { rating of perceived breathlessness } \\
\Delta \mathrm{S}_{\mathrm{pO}}=\% \text { arterial oxygen desaturation as indicated by pulse oximetry }\left(\mathrm{S}_{\mathrm{pO}_{2}} \text { rest }-\mathrm{S}_{\mathrm{pO}_{2}}\right. \\
\text { maximal exercise) }\end{array}$} \\
\hline
\end{tabular}

tionally, based on predicted values, $\mathrm{P}_{\operatorname{Imax}}$ was significantly decreased with obesity.

\section{Exercise Capacity}

Table 3 lists the peak exercise values obtained during testing. Comparison with predicted values for $\dot{\mathrm{V}}_{\mathrm{O}_{2}}$ demonstrate a decline of exercise capacity with obesity; however, heart rate, predicted values, and rate of exchange ratio $^{33}$ demonstrated maximal effort during testing and normal cardiorespiratory fitness for all 3 groups. Rates of perceived exercise were not significantly different between all 3 groups; however, RPB values were higher in massive obesity than in the mild obesity and control subjects. At maximal exercise, massive obesity was accompanied with a significant fall in $\mathrm{S}_{\mathrm{pO}_{2}}$ at end exercise $(-6 \pm 3 \%)$.

\section{Ventilatory Response to Exercise}

$\dot{\mathrm{V}}_{\mathrm{E}}$ is plotted against work rate in Fig. 1; significant differences were observed in $\dot{\mathrm{V}}_{\mathrm{E}}$ between obese and control subjects at rest and at VT. At peak exercise, obese class III had a lower $\dot{\mathrm{V}}_{\mathrm{E}}(P<.001)$ than both obese class II and control subjects. $\dot{\mathrm{V}}_{\mathrm{E}} / \mathrm{MVV}$ percentage was significantly higher $(P<.001)$ in the obese class III than in control subjects at peak exercise (Table 3 ). $\dot{\mathrm{V}}_{\mathrm{E}} / \mathrm{MVV}$ was 


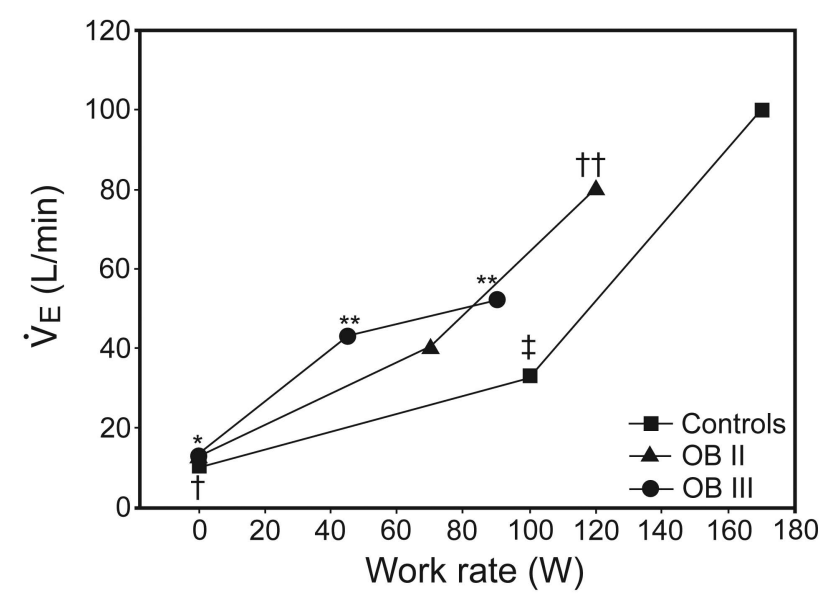

Fig. 1. Minute ventilation plotted against work rate. Comparisons are between groups. First, second, and third points represent data at rest, ventilatory threshold, and maximal exercise, respectively. Class III obesity (OB III) vs control: ${ }^{*}=P<.01,{ }^{*}=P<.001$; class II obesity (OB II) vs class III obesity: $\dagger=P<.05$, $\dagger \dagger=\mathrm{P}<$ .001 ; control vs class II obesity: $\ddagger=P<.001$.

not significantly different between obese class II and control subjects at peak exercise. Among all subjects, a significant correlation was observed between TLC and peak $\dot{\mathrm{V}}_{\mathrm{E}}(\mathrm{r}=0.88, P=.001) . \dot{\mathrm{V}}_{\mathrm{E}}$ was significantly correlated with BMI $(\mathrm{r}=-0.72, P=.001)$. As indicated in Fig. 1, obesity resulted in a progressive increase in $\dot{V}_{E}$ for a given submaximal work rate. The slope of $\dot{\mathrm{V}}_{\mathrm{E}}$ below VT (ie, between rest and VT) was significantly greater $(P<.001)$ in obese class III $(0.55 \pm 0.07 \mathrm{~L} / \mathrm{min} / \mathrm{W})$ than in control subjects $(0.27 \pm 0.09 \mathrm{~L} / \mathrm{min} / \mathrm{W})$ and obese class II subjects $(0.35 \pm 0.08 \mathrm{~L} / \mathrm{min} / \mathrm{W})$. The slope of $\dot{V}_{\mathrm{E}}$ above VT (ie, between VT and maximal exercise) was not significantly different between groups (slopes: $0.65 \pm 0.15$
$\mathrm{L} / \mathrm{min} / \mathrm{W} ; 0.60 \pm 0.12 \mathrm{~L} / \mathrm{min} / \mathrm{W} ; 0.63 \pm 0.1 \mathrm{~L} / \mathrm{min} / \mathrm{W}$, for control, obese class II, and obese class III groups, respectively). The slope of $\dot{\mathrm{V}}_{\mathrm{O}_{2}}$ versus work rate below VT was significantly higher in obese class III than control subjects $(P<.001) . \dot{\mathrm{V}}_{\mathrm{E}} / \dot{\mathrm{V}}_{\mathrm{O}_{2}}$ and $\dot{\mathrm{V}}_{\mathrm{E}} / \dot{\mathrm{V}}_{\mathrm{CO}_{2}}$ were significantly higher $(P<.001)$ at rest in the obese class III group than in the control and obese class II groups (Table 4). At VT, $\dot{\mathrm{V}}_{\mathrm{E}} / \dot{\mathrm{V}}_{\mathrm{O}_{2}}$ and $\dot{\mathrm{V}}_{\mathrm{E}} / \dot{\mathrm{V}}_{\mathrm{CO}_{2}}$ were significantly different $(P<.001)$ across all 3 groups. At peak exercise, $\dot{\mathrm{V}}_{\mathrm{E}} / \dot{\mathrm{V}}_{\mathrm{CO}_{2}}$ was significantly higher in the obese class III than the control $(P<.001)$ and obese class II groups $(P<.0)$. $\mathrm{P}_{\mathrm{ETCO}_{2}}$ was not significantly different between groups at rest and VT, however, at peak exercise, $\mathrm{P}_{\mathrm{ETCO}_{2}}$ was significantly higher $(P<.001)$ in obese class III than in control subjects. Dead space volume $\left(\mathrm{V}_{\mathrm{D}}\right) /$ tidal volume was estimated using $\mathrm{P}_{\mathrm{ETCO}_{2}}$ (Table 4). At rest, there was a trend for $\mathrm{V}_{\mathrm{D}} /$ tidal volume to increase with obesity, although no statistical differences were observed between groups. $\mathrm{V}_{\mathrm{D}} /$ tidal volume was significantly higher $(P<.001)$ in obese class III than in control and obese class II at VT and at maximal exercise.

\section{Breathing Mechanics}

EELV were plotted against $\dot{\mathrm{V}}_{\mathrm{E}}$ at rest, VT, and peak exercise (Fig. 2). EELV (\% TLC) was significantly lower in the obese subjects at rest $(P<.001)$, and during exercise at VT, but not during peak exercise. During heavy-to-peak exercise, the obese subjects increased EELV, whereas the control group continued to decrease EELV. Although both obese groups increased EELV during exercise above VT, only the obese class III group increased its EELV during exercise to levels above resting EELV. When the 3 groups were combined, resting EELV was significantly

Table 4. Selected Ventilatory Variables

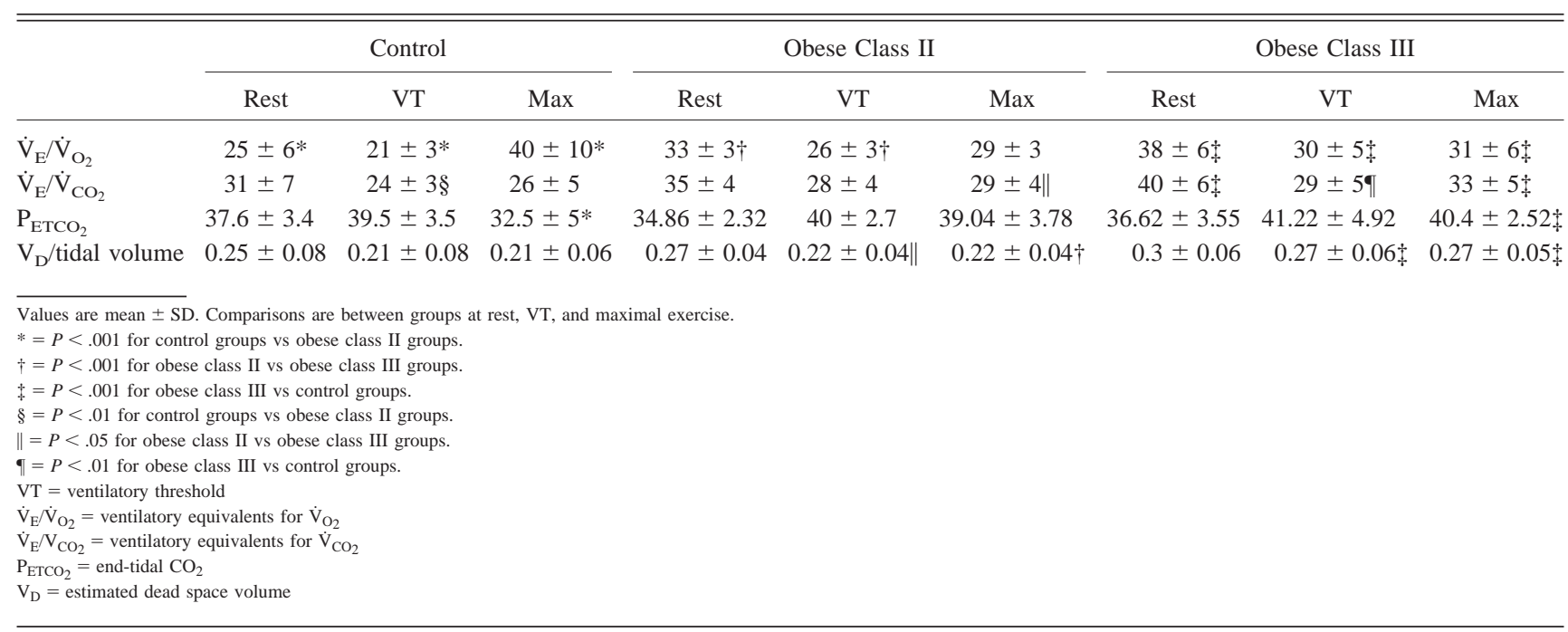




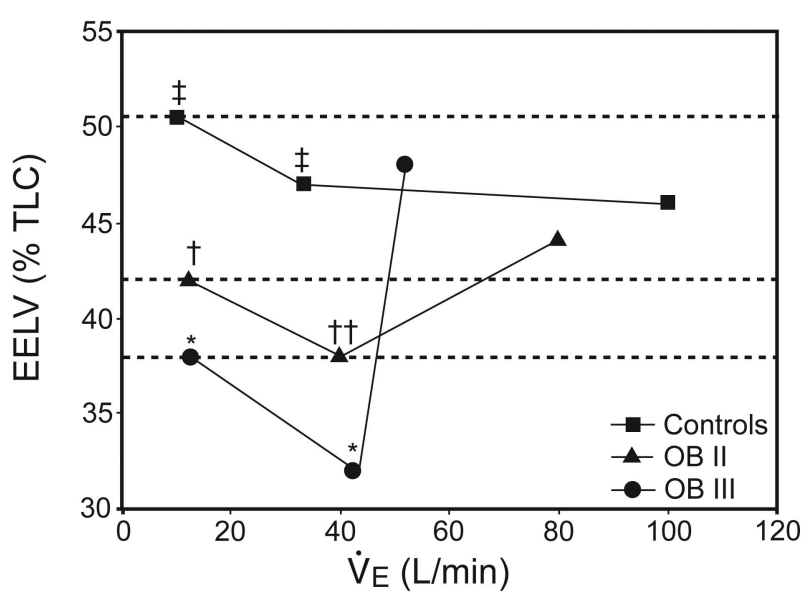

Fig. 2. End-expiratory lung volume (EELV) as a percentage of total lung capacity (TLC) plotted against minute ventilation $\left(\dot{V}_{E}\right)$. First, second, and third points represent data at rest, ventilatory threshold, and maximal exercise, respectively. Horizontal dashed lines indicate each group's resting EELV. Class III obesity (OB III) vs control: ${ }^{*}=P<.001$; class II obesity (OB II) vs class III obesity: $\dagger=P<.05, \dagger \dagger=P<.01$; control vs class II obesity: $\ddagger=P<001$.

correlated with weight $(\mathrm{r}=-0.66, P=.001)$, BMI $(\mathrm{r}=$ $-0.7, P=.001)$, and WHR $(\mathrm{r}=-0.72, P=.001)$. During peak exercise EELV was correlated with weight $(\mathrm{r}=0.7, P=.001)$, BMI $(\mathrm{r}=0.79, P=.001)$, and WHR $(\mathrm{r}=0.89, P=.001), \Delta \mathrm{S}_{\mathrm{pO}_{2}}(\mathrm{r}=0.72, P=.001)$, $\mathrm{P}_{\text {Imax }}(\mathrm{r}=-0.7, P=.001)$, and RPB $(\mathrm{r}=0.82$, $P=.001)$.

EILV (\% TLC) are plotted against $\dot{\mathrm{V}}_{\mathrm{E}}$ at rest, VT, and peak exercise (Fig. 3). EILV (\% TLC) was significantly lower in the obese class II subjects and obese class III at rest and VT but not during peak exercise. At maximal exercise, obese class III subjects had a greater EILV (\% TLC) than obese class II subjects and control subjects. When the 3 groups were combined, resting EILV was significantly correlated with weight $(\mathrm{r}=-0.7$, $P=.001)$, BMI $(\mathrm{r}=-0.74, P=.001)$, and WHR $(\mathrm{r}=-0.79, P=.001)$. At peak exercise, EILV (\% TLC) was correlated with weight $(\mathrm{r}=0.75, P=.001)$, BMI $(\mathrm{r}=$ $0.77, P=.001), \operatorname{WHR}(\mathrm{r}=0.81, P=.001), \Delta \mathrm{S}_{\mathrm{pO}_{2}}(\mathrm{r}=0.74$, $P=.001), \mathrm{P}_{\mathrm{Imax}}(\mathrm{r}=-0.72, P=.001)$, and $\mathrm{RPB}(\mathrm{r}=0.9$, $P=.001)$.

In Fig. 4, tidal volume and breathing frequency (f) are plotted against $\dot{\mathrm{V}}_{\mathrm{E}}$ at rest, VT, and peak exercise. No differences in tidal volume were observed between groups at rest. Obese class III had a lower tidal volume than control and obese class II subjects at VT $(P<.01)$ and peak exercise $(P<.001)$. Breathing frequency (f) was significantly increased by obesity. Obese class III subjects had a greater $\mathrm{f}$ relative to control and obese class II subjects at rest $(P<.05)$ and VT $(P<.001)$. At peak exercise, $f$ was significantly higher $(P<.001)$ in obese class III than obese class II and control group.

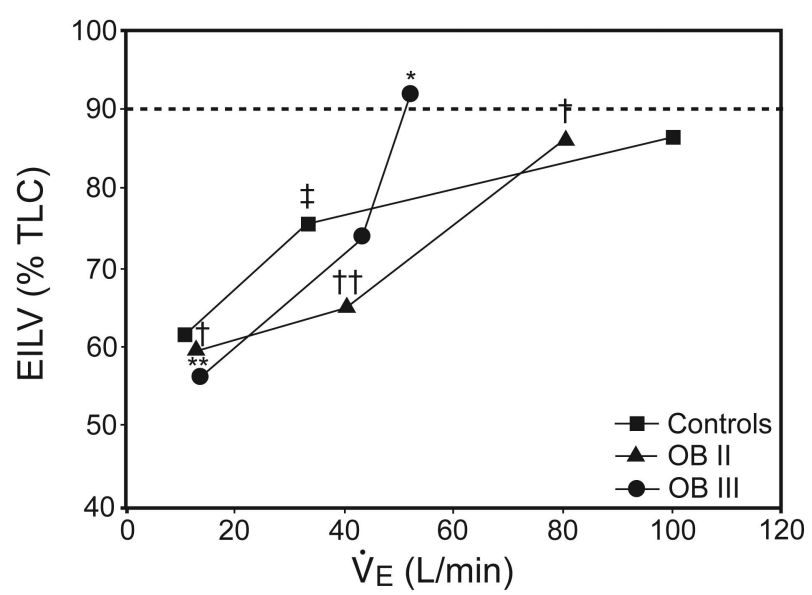

Fig. 3. End-inspiratory lung volume (EILV) as a percentage of total lung capacity (TLC) plotted against minute ventilation $\left(\dot{V}_{\mathrm{E}}\right)$. First, second, and third points represent data at rest, ventilatory threshold, and maximal exercise, respectively. The dashed line shows $90 \%$ of TLC. Class III obesity (OB III) vs control: ${ }^{*}=P<.01 ;{ }^{* \star}=P<.001$; class II obesity (OB II) vs class III obesity: $\dagger=P<.01$, $\dagger \dagger=P<.001$; control vs class II obesity: $\ddagger=P<.001$.

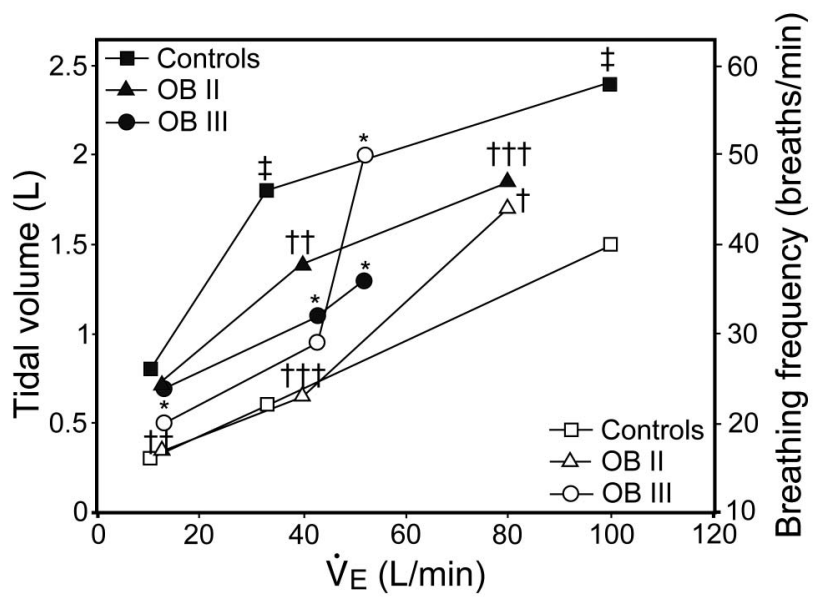

Fig. 4. Breathing pattern. Tidal volume (black symbols) and breathing frequency (white symbols) plotted against minute ventilation $\left(\dot{V}_{E}\right)$. First, second, and third points represent data at rest, ventilatory threshold, and maximal exercise, respectively. Class III obesity (OB III) vs control: ${ }^{*}=P<.001$; class II obesity (OB II) vs obese class III: $\dagger=P<.05$, $\dagger \dagger=P<.01$, $\dagger+\dagger=P<.001$; control vs class II obesity: $\ddagger=P<.001$.

Expiratory air flow limitation (EAFL \% tidal volume) is plotted against $\dot{\mathrm{V}}_{\mathrm{E}}$ at rest, VT, and peak exercise (Fig. 5). EAFL progressively increased with obesity. Obese class III experienced greater EAFL at rest (24.5\% tidal volume, $P<.001)$, VT $(36.5 \%$ tidal volume, $P<.001)$, and at peak exercise $(48 \%$ tidal volume, $P<.001)$ than both control and obese class II subjects. When the 3 groups were combined, resting EAFL (\% tidal volume) was significantly correlated with weight $(\mathrm{r}=0.7, P=$ 


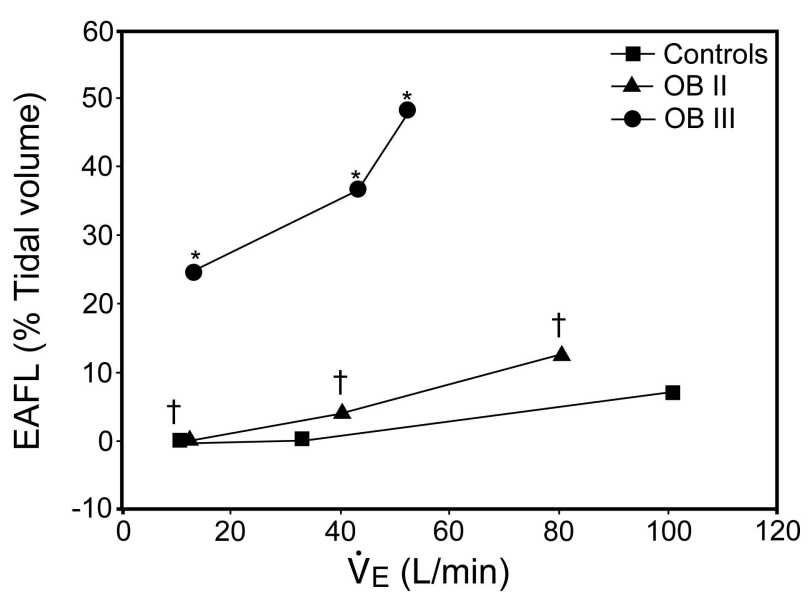

Fig. 5. Expiratory airflow limitation (EAFL) as a percentage of tidal volume plotted against minute ventilation $\left(\dot{V}_{E}\right)$. First, second, and third points represent data at rest, ventilatory threshold, and maximal exercise, respectively. Class III obesity (OB III) vs control: ${ }^{*}=P<.001$; class II obesity (OB II) vs obese class III: $\dagger=P<.001$.

$.001)$, BMI $(\mathrm{r}=0.81, P=.001)$, and WHR $(\mathrm{r}=0.85$, $P=.001$ ). During peak exercise EAFL (\% tidal volume) was correlated with weight $(\mathrm{r}=0.71, P=.001)$, BMI $(\mathrm{r}=0.88, P=.001)$, and WHR $(\mathrm{r}=0.86, P=.001)$, $\Delta \mathrm{S}_{\mathrm{pO}_{2}}(\mathrm{r}=0.72, P=.001), \mathrm{P}_{\text {Imax }}(\mathrm{r}=-0.79, P=.001)$, and RPB ( $=0.87, P=.001)$.

\section{Discussion}

Our present findings indicate that mechanical constraints on $\dot{\mathrm{V}}_{\mathrm{E}}$ during exercise increase progressively with obesity, because massively obese subjects demonstrated marked mechanical ventilatory constraints and an increased ventilatory requirement during exercise. These ventilatory constraints were evidenced by increases in EELV and EILV (which limited the VT reserve) and by expiratory flow limitation. The constraints appear to be closely related to exertional dyspnea and hypoxemia. To the best of our knowledge, this is the first study to examine the extent of ventilatory constraints in massive obesity and to determine how these constraints affect the ventilatory response to exercise.

\section{The Ventilatory Response to Exercise}

In this study, obese class III subjects displayed an elevated $\dot{\mathrm{V}}_{\mathrm{E}}$ for a given submaximal work rate below VT. Obese individuals tend to have a rapid and shallow breathing pattern both at rest ${ }^{34}$ and during exercise. ${ }^{35}$ Presumably, adopting a more rapid, shallow breathing pattern optimizes $\mathrm{WOB}^{36}$ and helps avoid diaphragmatic muscle fatigue. ${ }^{37} \mathrm{~A}$ rapid, shallow breathing pattern can reduce peak inspiratory muscle effort and, therefore, optimize the
$\mathrm{O}_{2}$ cost of breathing because, for a given $\dot{\mathrm{V}}_{\mathrm{E}}$, the combination of smaller tidal volume and higher $\mathrm{f}$ is most efficient by reducing the loading-related increased elastic forces. However, this breathing pattern becomes disadvantageous as dead space increases and the $\mathrm{O}_{2}$ cost of breathing increases with increasing $f$ that is a lower ventilatory efficiency. ${ }^{38}$ Indeed, our results demonstrate that the slope of the linear $\dot{\mathrm{V}}_{\mathrm{E}} / \dot{\mathrm{V}}_{\mathrm{CO}_{2}}$ relationship as an index of ventilatory inefficiency increased with obesity. ${ }^{21}$ Hence, observation of a greater $\dot{\mathrm{V}}_{\mathrm{E}} / \dot{\mathrm{V}}_{\mathrm{CO}_{2}}$ ratio at rest and at $\mathrm{VT}$ in the obese class III argues in favor of an increase in dead space ventilation. Estimates of $\mathrm{V}_{\mathrm{D}} /$ tidal volume also revealed a tendency for the dead space to increase with obesity. However, if the increase in tidal volume was indeed limited by mechanical constraints in the obese class III, $\mathrm{V}_{\mathrm{D}} /$ tidal volume should have been higher in these subjects, relative to the other 2 groups. Our results demonstrate that exercise tolerance decreased with increasing obesity. ${ }^{36}$ This reduction is thought to be due to the added energy needed to move the fat mass during exercise. $\dot{\mathrm{V}}_{\mathrm{O}_{2}}$ and $\dot{\mathrm{V}}_{\mathrm{E}}$ were found to be higher in moderate to severe obese individuals ${ }^{39}$ than in control subjects during exercise at comparable work rates. The increased $\dot{\mathrm{V}}_{\mathrm{O}_{2}}$ required for a given work load in obesity was thought to be due to the greater metabolic energy needed to move the increased body mass (ie, the increased leg mass) or to an increased WOB. ${ }^{40} \dot{\mathrm{V}}_{\mathrm{E}} / \dot{\mathrm{V}}_{\mathrm{O}_{2}}$ is greater at rest and during exercise ${ }^{41}$ in obese class III individuals, which implies reduced ventilatory efficiency. The physiological consequences of this relative inefficiency correspond to a reduction in the ventilatory reserve and a disturbance of homeostasis.

The observed increase in the slope of $\dot{\mathrm{V}}_{\mathrm{O}_{2}}$ versus work rate below VT in our obese class III suggests that the latter had an increased metabolic demand. According to Hansen and colleagues, ${ }^{42}$ the slope for 1 -min incremental cycle ergometer work is $10.2 \pm 1.0 \mathrm{~mL} \mathrm{O} / \mathrm{min} / \mathrm{W}$ for normal subjects. Our obese class III had a mean slope of $15.5 \pm 6 \mathrm{~mL} \mathrm{O}_{2} / \mathrm{min} / \mathrm{W}$. This increase and the likelihood of an increased WOB are factors which could potentially contribute to the observed increased metabolic demand. Normally, for a given increment in work rate, $\dot{\mathrm{V}}_{\mathrm{E}}$ increases at a greater rate above VT than below VT. The ventilatory response to exercise above VT appears to be adequate in the obese class III because the groups did not differ in terms of the slope of $\dot{V}_{\mathrm{E}}$ versus work rate above VT. Consequently, as a result of increased ventilatory demand during submaximal exercise, the obese class III began to encounter mechanical ventilatory constraints relatively early in the exercise session. Thus, it appears that our obese class III had already used a large portion of their ventilatory capacity before reaching VT and were prevented from further increasing $\dot{V}_{\mathrm{E}}$ by mechanical constraints. If there is a progressive increase in mechanical ventilatory constraints with obesity, one would predict that 
obese class III would have an even smaller ventilatory reserve in which to accommodate an increased ventilatory demand. In agreement with several other studies, we observed a decline in $\dot{\mathrm{V}}_{\mathrm{E}}$ and an increase in $\dot{\mathrm{V}}_{\mathrm{E}}$ /MVV at peak exercise in obese class III (Table 3). Decrease in MVV may be explained by respiratory muscle inefficiency, increased upper airway resistance, and inspiratory flow resistance. ${ }^{8,9,43}$ The decline in MVV in obesity may be due to increased tissue resistance, increased intra-abdominal pressure in obese persons, exaggeration of the normal spinal curvature due to forward displacement of the center of gravity of the body thus causing profound thoracic kyphosis. It leads to elevation of the lower sternum and relative fixation of the chest in a position of moderate inspiration and consequently reduced expiratory reserve volume. ${ }^{43,44}$ Although $\dot{\mathrm{V}}_{\mathrm{E}} / \mathrm{MVV}$ is commonly used as an indicator of ventilatory constraint, it has been shown to be a poor indicator of mechanical ventilatory constraints and is misleading in mild COPD. ${ }^{45}$ This is probably also true for the obese class III.

\section{Breathing Mechanics}

The most distinctive mechanical effect of obesity is the decrease in EELV at rest and the subsequent increase at maximal exercise. ${ }^{46}$ The decreased EELV likely reflects the decreased chest wall and lung compliance known to be associated with obesity. ${ }^{3,5,8,47,48}$ The reduced EELV at rest associated with obesity appears to influence the regulation of EELV during heavy-to-peak exercise. This occurs by placing the obese subject at a lung volume that predisposes him to high expiratory resistance and expiratory flow limitation, which necessitates an increase in EELV to increase $\dot{\mathrm{V}}_{\mathrm{E}}$ in concert with exercise intensity. $8,43,49,50$ Obese subjects adopt this strategy because (1) maximal expiratory flows decrease progressively with decreasing lung volume, and so breathing at a low lung volume is necessarily associated with a reduction in the expiratory flow reserve, which can fall even more in the presence of airway obstruction, and (2) maintaining an adequate VT would imply the need to reduce EELV.

Ventilatory reserve depends on 2 main factors: ventilatory demand and ventilator capacity. In our study, ventilatory capacity is affected by mechanical factors such as air flow limitation, operating lung volumes, and ventilatory muscle function. ${ }^{51}$ Thus, a reduction in ventilatory reserve may be explained by increased ventilatory demand during exercise) and/or reduced ventilatory capacity typically due to air flow limitation. Our result demonstrate that MVV, which measures both ventilatory mechanics and respiratory muscle function, was reduced in excessively obese subjects who had dyspnea. ${ }^{32,52}$ Our data demonstrate a progressive decrease in maximal ventilatory variables with obesity. MVV decreases with increasing BMI, suggesting that respiratory muscle function may play a substantial role in dyspnea and exercise intolerance. . $^{8,44,53}$ At the very least, it is plausible that impaired respiratory muscle function will impair ventilatory mechanics and produce dyspnea and exercise intolerance..$^{53-55}$

In our study, obese subjects demonstrated a tendency to decrease $\mathrm{P}_{\text {Imax, }}$ when expressed as a percentage of the predicted value at an equivalent lung volume. The reduced inspiratory muscle strength indicated by $\mathrm{P}_{\text {Imax }}$ values confirms earlier reports. ${ }^{56}$ It may be beneficial to keep EELV low, to optimize inspiratory muscle length and force production. The regulation of EELV during exercise was similar during submaximal exercise in the control and obese subjects, with all groups decreasing EELV between rest and VT. A decrease in EELV constitute one of the most prominent effects of mild obesity on pulmonary function. ${ }^{3}$ As a result, EELV does not drop farther during exercise in contrast to that in normal subjects. Thus, there appears to be a lower limit to end-tidal volume, although the mechanism of this lower limit is unclear. Nevertheless, the lower EELV means that: (1) the work of breathing is not partitioned between the expiratory and inspiratory muscles, (2) there is an increased load on the inspiratory muscles to increase $\mathrm{V}_{\mathrm{T}}$ during exercise, and (3) there is an increased potential for expiratory flow limitation resulting from breathing at such a low EELV. ${ }^{3}$ All these effects increase the mechanical ventilatory constraints to exercise in the obese. This response is in agreement with earlier reports. , $^{3,5-7}$ However, during heavy to maximal exercise, normal subjects continued to decrease EELV from VT to peak exercise, whereas the obese subjects further increased EELV. It is important to recognize that EELV increases during exercise in massive obesity, decreasing the IC. This dynamic hyperinflation (DH) increases the respiratory system's ability to generate expiratory flow but also limits the maximum tidal volume and reduces the inspiratory muscles' ability to produce force by reducing their length, leading to the sensation of breathlessness..$^{57,58} \mathrm{We}$ found an excellent correlation between DH (ie, the increase in EELV) and dyspnea; it is well known that DH is an important contributor to the intensity and quality of dyspnea. ${ }^{59,60}$ This finding is in accordance with other studies reporting frequent complaints of exertional dyspnea in obese subjects. ${ }^{61}$ Diaphragmatic fatigue has not been consistently observed in obese subjects after incremental exercise but the sensation of dyspnea may act as a protective mechanism, reaching intolerable levels before the muscles actually fatigue. Our result contrast with the result of Ofir et al, ${ }^{7}$ which showed that the increases in EELV with exercise served to optimize operating lung volumes and to attenuate expiratory flow limitation so as to accommodate the increased ventilatory demand without increased breathlessness. 
As ventilatory demand increases and the subject increases his/her EELV to avoid expiratory flow limitation and to take advantage of the higher available maximal expiratory air flows, EILV increases to maintain VT. ${ }^{2}$ When increases in EELV are coupled with an EILV approaching the TLC ceiling, the VT reserve is reduced, thus limiting VT. EILV averaged (86\%) of the TLC in the obese class II and reached $(92-97 \%)$ in obese class III. Johnson and colleagues ${ }^{20}$ reported that a high EILV ( $>90 \%$ of a subject's TLC) results in increased ventilatory muscle work. Furthermore, many obese class III subjects experience EAFL, which can result in further increases in EELV. ${ }^{30,31,46}$ In the present study, obese class III subjects experienced EAFL \% tidal volume at rest and throughout exercise. Expiratory air flow limitation promotes $\mathrm{DH}$ with a concurrent increase in the WOB, due to presence of intrinsic PEEP. ${ }^{31,46}$ The inhomogeneity of intrinsic PEEP within the lung (which is present under these conditions) may also contribute to impaired arterial oxygenation. Hypoxia has been found to increase EELV in healthy subjects and in patients with interstitial lung disease. ${ }^{62}$ Our results demonstrate that massive obesity resulted in greater gas exchange abnormalities. Obesity caused a significant increase in $\Delta \mathrm{S}_{\mathrm{pO}_{2}}$ and an increased $\mathrm{P}_{\mathrm{ETCO}}$ toward the end of progressive exercise, which probably reflected decompensation of the respiratory system with some degree of alveolar hypoventilation. Other potential explanations for $\mathrm{S}_{\mathrm{pO}_{2}}$ desaturation during exercise with massive obesity include increased ventilationperfusion abnormalities. ${ }^{63}$

There are certain limitations of the present study. First, the $\mathrm{P}_{\text {Imax }}$ test is volitional and requires full cooperation. Accordingly, a low result may be due to lack of motivation and does not necessarily indicate reduced inspiratory or expiratory muscle strength. In future studies, it is preferable to use the sniff test or phrenic nerve stimulation.

Second, reduction in oxygenation is unlikely to be due to abnormalities of gas transfer. Measurement of gas diffusion can be useful because a decreased diffusing capacity is associated with arterial desaturation during exercise.

Finally, we relied on pulse oximetry to define gas exchange abnormalities, which may not be sensitive to small changes in oxygen tension. We did not measure arterial blood gases in this study. However, we believe that exercise oximetry is a clinically relevant test, because it is easily performed in the office setting and is generally accurate for important levels of desaturation.

\section{Conclusions}

Exercise limitation is a major feature of obesity. The impaired exercise performance in obese subjects is largely due to failure of the available ventilatory reserve to meet increasing ventilatory demands, as a result of increased ventilatory loads and impaired ventilatory muscle func- tion. In the present study, obese class III subjects displayed a reduced VT reserve and used increases in $f$ early in exercise to boost $\dot{V}_{\mathrm{E}}$. This strategy was effective until they began to experience marked EAFL during exercise. The development of dynamic hyperinflation with a progressive increase in EELV imposes additional elastic load on the ventilatory system and is closely related to exertional dyspnea and hypoxemia; it therefore contributes to exercise limitation in obese class III subjects.

\section{ACKNOWLEDGMENTS}

We thank the medical staff of the Department of Cardiac Rehabilitation of Corbie Hospital for their technical assistance and the obese subjects from the Nutritional and Physical Rehabilitation Department of Corbie Hospital for their dedication to the study.

\section{REFERENCES}

1. Dueck R. Assessment and monitoring of flow limitation and other parameters from flow/volume loops. J Clin Monit Comput 2000; 16(5-6):425-432.

2. Johnson BD, Weisman IM, Zeballos RJ, Beck KC. Emerging concepts in the evaluation of ventilatory limitation during exercise: the exercise tidal flow-volume loop. Chest 1999;116(2):488-503.

3. Babb TG. Mechanical ventilatory constraints in aging, lung disease, and obesity: perspectives and brief review. Med Sci Sports Exerc 1999;31(1 Suppl):S12-22.

4. Tantucci C. Expiratory flow limitation definition, mechanisms, methods, and significance. Pulm Med 2013;749860, 2013.

5. Babb TG, DeLorey DS, Wyrick BL, Gardner PP. Mild obesity does not limit change in end-expiratory lung volume during cycling in young women. J Appl Physiol 2002;92(6):2483-2490.

6. DeLorey DS, Wyrick BL, Babb TG. Mild-to-moderate obesity: implications for respiratory mechanics at rest and during exercise in young men. Int J Obes 2005;29(9):1039-1047.

7. Ofir D, Laveneziana P, Webb KA, O'Donnell DE. Ventilatory and perceptual responses to cycle exercise in obese women. J Appl Physiol 2007;102(6):2217-2226.

8. Babb TG. Obesity: challenges to ventilatory control during exercise-a brief review. Respir Physiol Neurobiol 2013;189(2):364370.

9. Redlich CA, Tarlo SM, Hankinson JL, Townsend MC, Eschenbacher WL, Von Essen SG, et al. Official American Thoracic Society technical standards: spirometry in the occupational setting. Am J Respir Crit Care Med 2014;189(8):983-993.

10. Johannessen A, Omenaas ER, Eide GE, Bakke PS, Gulsvik A. Feasible and simple exclusion criteria for pulmonary reference populations. Thorax 2007;62(9):792-798.

11. ATS/ERS. Standardization of lung function testing: standardization of spirometry. Eur Respir J 2005;26:319-338.

12. Castellsagué J, Burgos F, Sunyer J, Barberà JA, Roca J. Prediction equations for forced spirometry from European origin populations. Barcelona Collaborative Group on Reference Values for Pulmonary Function Testing and the Spanish Group of the European Community Respiratory Health Survey. Respir Med 1998;92(3):401-407.

13. Black LF, Hyatt RE. Maximal respiratory pressures: normal values and relationship to age and sex. Am Rev Respir Dis 1969;99(5):696702.

14. Harik-Khan RI, Wise RA, Fozard JL. Determinants of maximal inspiratory pressure: the Baltimore Longitudinal Study of Aging. Am J Respir Crit Care Med 1998;158(5 Pt 1):1459-1464. 


\section{Exercise Air Flow Limitation in Obese Subjects}

15. Bussotti M, Agostoni P, Durigato A, Santoriello C, Farina S, Brusasco V, et al. Do maximum flow-volume loops collected during maximum exercise test alter the main cardiopulmonary parameters? Chest J 2009;135(2):425-433.

16. Babb TG. Ventilatory response to exercise in subjects breathing $\mathrm{CO} 2$ or HeO2. J Appl Physiol 1997;82(3):746-754.

17. Bae J, Ting EY, Giuffrida JG. The effect of changes in the body position obsese patients on pulmonary volume and ventilatory function. Bull NY Acad Med 1976;52(7):830-837.

18. Younes M, Kivinen G. Respiratory mechanics and breathing pattern during and following maximal exercise. J Appl Physiol 1984;57(6): 1773-1782.

19. Stubbing DG, Pengelly LD, Morse JL, Jones NL. Pulmonary mechanics during exercise in normal males. J Appl Physiol 1980;49(3): 506-510.

20. Johnson BD, Beck KC, Zeballos RJ, Weisman IM. Advances in pulmonary laboratory testing. Chest 1999;116(5):1377-1387.

21. Wasserman K. Principles of exercise testing and interpretation: including pathophysiology and clinical applications 4th edition. Philadelphia: Lippincott Williams \& Wilkins; 2005.

22. Caiozzo VJ, Davis JA, Ellis JF, Azus JL, Vandagriff R, Prietto CA, McMaster WC. A comparison of gas exchange indices used to detect the anaerobic threshold. J Appl Physiol 1982;53(5):1184-1189.

23. Wasserman K. Principles of exercise testing \& interpretation: including pathophysiology and clinical applications 3rd edition. Philadelphia: Lippincott Williams \& Wilkins; 1999.

24. Wasserman K, Stringer WW, Casaburi R, Koike A, Cooper CB. Determination of the anaerobic threshold by gas exchange: biochemical considerations, methodology and physiological effects. Zeitschrift fur Kardiologie 83 Suppl 3:1-12, 1994.

25. Beaver WL, Wasserman K, Whipp BJ. A new method for detecting anaerobic threshold by gas exchange. J Appl Physiol 1986;60(6): 2020-2027.

26. Dempsey JA, Wagner PD. Exercise-induced arterial hypoxemia. J Appl Physiol 1999;87(6):1997-2006.

27. Borg GA. Psychophysical bases of perceived exertion. Med Sci Sports Exerc 1982;14(5):377-381.

28. Johnson BD, Scanlon PD, Beck KC. Regulation of ventilatory capacity during exercise in asthmatics. J Appl Physiol 1995;79(3):892901.

29. Wasserman K, Hansen J, Sue D, Whipp B, Casaburi R. Principles of exercise testing and interpretation. Philadelphia: Lea \& Febiger; 1994.

30. Baydur A, Wilkinson L, Mehdian R, Bains B, Milic-Emili J. Extrathoracic expiratory flow limitation in obesity and obstructive and restrictive disorders: effects of increasing negative expiratory pressure. Chest 2004;125(1):98-105.

31. Pankow W, Podszus T, Gutheil T, Penzel T, Peter J, Von Wichert P. Expiratory flow limitation and intrinsic positive end-expiratory pressure in obesity. J Appl Physiol 1998;85(4):1236-1243.

32. Sahebjami H, Gartside PS. Pulmonary function in obese subjects with a normal FEV1/FVC ratio. Chest 1996;110(6):1425-1429.

33. Jones NL, Makrides L, Hitchcock C, Chypchar T, McCartney N. Normal standards for an incremental progressive cycle ergometer test. Am Rev Respir Dis 1985;131(5):700-708.

34. Sampson MG, Grassino K. Neuromechanical properties in obese patients during carbon dioxide rebreathing. Am J Med 1983;75(1): 81-90.

35. Sakamoto S, Ishikawa K, Senda S, Nakajima S, Matsuo H. The effect of obesity on ventilatory response and anaerobic threshold during exercise. J Med Syst 1993;17(3-4):227-231.

36. Wang LY, Cerny FJ. Ventilatory response to exercise in simulated obesity by chest loading. Med Sci Sports Exerc 2004;36(5):780-786.
37. Ambrosino N, Opasich C, Crotti P, Cobelli F, Tavazzi L, Rampulla C. Breathing pattern, ventilatory drive and respiratory muscle strength in patients with chronic heart failure. Eur Respir J 1994;7(1):17-22.

38. Neder JA, Dal Corso S, Malaguti C, Reis S, De Fuccio MB, Schmidt $\mathrm{H}$, et al. The pattern and timing of breathing during incremental exercise: a normative study. Eur Respir J 2003;21(3):530-538.

39. Salvadori A, Fanari P, Cavestri R, Mazza P, Baudo S, Longhini E. Relationship between body mass and tolerance to physical stress in obese patients. Respiration 1991;58(5-6):311-315.

40. American Thoracic Society, American College of Chest Physicians. Statement on cardiopulmonary exercise testing. Am J Respir Crit Care Med 2003;167(2):211-277.

41. Whipp BJ, Davis JA. The ventilatory stress of exercise in obesity. Am Rev Respir Dis 1984;129(2 Pt 2):S90-92.

42. Hansen JE, Sue DY, Wasserman K. Predicted values for clinical exercise testing. Am Rev Respir Dis 1984;129(2 Pt 2):S49-55.

43. Dixon AEC-BEM. Obesity and lung disease: a guide to management. New York: Springer; 2013.

44. Lin CK, Lin CC. Work of breathing and respiratory drive in obesity. Respirology 2012;17(3):402-411.

45. Babb TG, Rodarte JR. Estimation of ventilatory capacity during submaximal exercise. J Appl Physiol 1993;74(4):2016-2022.

46. Ferretti A, Giampiccolo P, Cavalli A, Milic-Emili J, Tantucci C. Expiratory flow limitation and orthopnea in massively obese subjects. Chest 2001;119(5):1401-1408.

47. Pellegrino R, Brusasco V, Rodarte JR, Babb TG. Expiratory flow limitation and regulation of end-expiratory lung volume during exercise. J Appl Physiol 1993;74(5):2552-2558.

48. Romagnoli I, Laveneziana P, Clini EM, Palange P, Valli G, de Blasio $\mathrm{F}$, et al. Role of hyperinflation vs. deflation on dyspnoea in severely to extremely obese subjects. Acta Physiol 2008;193(4):393-402.

49. Sebastian JC. Respiratory physiology and pulmonary complications in obesity. Best Pract Res Clin Endocrinol Metabol 2013;27(2):157161.

50. Littleton SW. Impact of obesity on respiratory function. Respirology 2012;17(1):43-49.

51. Watson RA, Pride NB. Postural changes in lung volumes and respiratory resistance in subjects with obesity. J Appl Physiol 2005;98(2): 512-517.

52. Sahebjami H. Dyspnea in obese healthy men. Chest 1998;114(5): 1373-1377.

53. Chlif M, Keochkerian D, Mourlhon C, Choquet D, Ahmaidi S. Noninvasive assessment of the tension-time index of inspiratory muscles at rest in obese male subjects. Int J Obes 2005;29(12):1478-1483.

54. Chlif M, Keochkerian D, Choquet D, Vaidie A, Ahmaidi S. Effects of obesity on breathing pattern, ventilatory neural drive and mechanics. Respir Physiol Neurobiol 2009;168(3):198-202.

55. Chlif M, Keochkerian D, Feki Y, Vaidie A, Choquet D, Ahmaidi S. Inspiratory muscle activity during incremental exercise in obese men. Int J Obes 2007;31(9):1456-1463.

56. Weiner P, Waizman J, Weiner M, Rabner M, Magadle R, Zamir D. Influence of excessive weight loss after gastroplasty for morbid obesity on respiratory muscle performance. Thorax 1998;53(1):39-42.

57. O'Donnell DE, Bain DJ, Webb KA. Factors contributing to relief of exertional breathlessness during hyperoxia in chronic airflow limitation. Am J Respir Crit Care Med 1997;155(2):530-535.

58. O'Donnell DE, Webb KA. Exertional breathlessness in patients with chronic airflow limitation: the role of lung hyperinflation. Am Rev Respir Dis 1993;148(5):1351-1357.

59. O'Donnell DE, Bertley JC, Chau LK, Webb KA. Qualitative aspects of exertional breathlessness in chronic airflow limitation: pathophysiologic mechanisms. Am J Respir Crit Care Med 1997;155(1):109115 . 


\section{Exercise Air Flow Limitation in Obese Subjects}

60. Marin JM, Carrizo SJ, Gascon M, Sanchez A, Gallego B, Celli BR. Inspiratory capacity, dynamic hyperinflation, breathlessness, and exercise performance during the 6-minute-walk test in chronic obstructive pulmonary disease. Am J Respir Crit Care Med 2001;163(6): 1395-1399.

61. Gibson GJ. Obesity, respiratory function and breathlessness. Thorax 2000;55 (Suppl 1):S41-44.
62. Marciniuk DD, Sridhar G, Clemens RE, Zintel TA, Gallagher CG. Lung volumes and expiratory flow limitation during exercise in interstitial lung disease. J Appl Physiol 1994;77(2):963-973.

63. Koutsoukou A, Koulouris N, Bekos B, Sotiropoulou C, Kosmas E, Papadima K, Roussos C. Expiratory flow limitation in morbidly obese postoperative mechanically ventilated patients. Acta Anaesthesiol Scand 2004;48(9):1080-1088. 